\title{
Normal muscle glucose uptake in mice deficient in muscle GLUT4
}

\author{
Barbara C Fam, Laura J Rose, Rebecca Sgambellone, Zheng Ruan, Joseph Proietto and \\ Sofianos Andrikopoulos \\ Department of Medicine (Austin Health), Austin Hospital, University of Melbourne, Level 7, Lance Townsend Building, Studley Road, Heidelberg, Victoria 3084, \\ Australia \\ (Correspondence should be addressed to B C Fam; Email: bcfam@unimelb.edu.au)
}

\begin{abstract}
Skeletal muscle insulin resistance is a major characteristic underpinning type 2 diabetes. Impairments in the insulin responsiveness of the glucose transporter, Glut4 (Slc2a4), have been suggested to be a contributing factor to this disturbance. We have produced muscle-specific Glut 4 knockout $(\mathrm{KO})$ mice using Cre/LoxP technology on a C57BL6/J background and shown undetectable levels of GLUT4 in both skeletal muscle and heart. Our aim was to determine whether complete deletion of muscle GLUT4 does in fact lead to perturbations in glucose homoeostasis. Glucose tolerance, glucose turnover and 2-deoxyglucose uptake into muscle and fat under basal and insulin-stimulated conditions were assessed in 12-week-old $\mathrm{KO}$ and control mice using the oral glucose tolerance test (OGTT) and hyperinsulinaemic/euglycaemic clamp respectively. $\mathrm{KO}$ mice weighed $\sim 17 \%$ less and had significantly heavier
\end{abstract}

hearts compared with control mice. Basally, plasma glucose and plasma insulin were significantly lower in the KO compared with control mice, which conferred normal glucose tolerance. Despite the lack of GLUT4 in the KO mouse muscle, glucose uptake was not impaired in skeletal muscle but was reduced in heart under insulin-stimulated conditions. Neither GLUT1 nor GLUT12 protein levels were altered in the skeletal muscle or heart tissue of our KO mice. High-fat feeding did not alter glucose tolerance in the KO mice but led to elevated plasma insulin levels during the glucose tolerance test. Our study demonstrates that deletion of muscle GLUT4 does not adversely affect glucose disposal and glucose tolerance and that compensation from other transporters may contribute to this unaltered homoeostasis of glucose.

Journal of Endocrinology (2012) 214, 313-327

\section{Introduction}

The inadequate response of the body to reduce high blood glucose levels can lead to the development of type 2 diabetes. This state of hyperglycaemia is contributed by three main defects: increased glucose production from the liver, a diminished capacity of the pancreas to secrete insulin and impaired insulin action on muscle and fat (DeFronzo et al. 1992, Stumvoll et al. 2005). Studies have shown that the primary defect in insulin action in individuals with type 2 diabetes resides predominantly within the skeletal muscle (DeFronzo et al. 1981, Utriainen et al. 1998, Pendergrass et al. 2007). Skeletal muscle insulin resistance is apparent long before the hyperglycaemia becomes evident (Warram et al. 1990), as demonstrated in lean, normal glucose-tolerant offspring of parents with type 2 diabetes who have a similar degree of reduced glucose uptake to that of their parents (Gulli et al. 1992, Perseghin et al. 1997, Ferrannini et al. 2003, Tripathy et al. 2003). Individuals with no family history of diabetes but with accompanying metabolic abnormalities such as obesity, hypertension, ischaemic heart disease, dyslipidaemia and polycystic ovary syndrome have also reported some degree of skeletal muscle insulin resistance
(Ginsberg et al. 1975, Ferrannini et al. 1987, Bressler et al. 1996, Kahn et al. 2006, Lankarani et al. 2009).

The disposal of glucose into muscle and adipose tissue is dependent on the action of specific glucose transporters (GLUT) and the hormonal regulation of their expression and function (Charron et al. 2005). The Glut4 (Slc2a4) is the main insulin-responsive transporter abundantly expressed in skeletal muscle, adipose tissue and heart (Kahn 1992, Mueckler 1994). In the resting state, GLUT4 is sequestered in intracellular vesicles and becomes translocated to the plasma membrane upon insulin stimulation to facilitate glucose transport into the cell (James \& Piper 1994, James et al. 1994, Hanpeter \& James 1995). In adipose tissue, GLUT4 mRNA and protein levels are downregulated in the setting of obesity or type 2 diabetes in both rodents and humans (Graham \& Kahn 2007). By contrast, skeletal muscle GLUT4 expression remains intact in these conditions, but alterations in the distribution of GLUT4 between intracellular membranes and the plasma membrane and in insulin-stimulated translocation to the plasma membrane can result in impaired glucose transport (Shepherd \& Kahn 1999).

Genetically modifying GLUT4 expression to determine the physiological consequences on glucose homoeostasis has 
been previously documented over the last two decades. In light of the importance of GLUT4 in mediating insulinstimulated glucose uptake, genetic ablation of this gene would be expected to have a severe effect on glucose homoeostasis. However, the results from these studies have conveyed different messages on glucose metabolism patterns. Mice that have a complete ablation of GLUT4 do not develop type 2 diabetes. In fact, these mice are growth retarded, have significant cardiac hypertrophy, reduced body weight and adiposity levels and are less sensitive to insulin action (Katz et al. 1995). Studies using ex vivo muscle tissue from these mice have shown normal glucose uptake into heart (Stenbit et al. 2000) but impaired uptake into skeletal muscle (Ryder et al. 1999b). In addition, conflicting results in mice with $50 \%$ GLUT4 deletion have also been reported. Rossetti et al. (1997) showed that heterozygous knockout (KO) mice developed severe insulin resistance in muscle in the face of normal fasting glucose levels while Stenbit et al. (1997) reported development of type 2 diabetes by 6 months of age, which was associated with reduced glucose uptake into muscle. To our knowledge, there has only been two models of muscle-specific GLUT4 deletion published (Zisman et al. 2000, Kim et al. 2001, Kaczmarczyk et al. 2003). Zisman et al. (2000) reported normal body weights and total body fat but cardiac hypertrophy in the muscle-specific $\mathrm{KO}$ mice that was associated with impaired insulin-stimulated glucose uptake into muscle and adipose tissue as well as an impaired suppression of hepatic glucose production and elevated fasting glucose levels. The following year, the same authors confirmed this finding using hyperinsulinaemic/euglycaemic clamps (Kim et al. 2001). Our own laboratory has reported that muscle-specific deletion of GLUT4 leads to reduced insulin-stimulated glucose uptake into muscle but not into adipose tissue. Moreover, these mice displayed normal glucose uptake into heart when mice expressed $>15 \%$ of GLUT4 but glucose uptake became markedly reduced when mice had $<5 \%$ of normal levels (Kim et al. 2001, Kaczmarczyk et al. 2003). Interestingly, the cardiac hypertrophy exhibited by other models was only evident in these mice when they showed the lower level of GLUT4 expression (Kaczmarczyk et al. 2003).

It seems from the earlier studies that deletion of GLUT4 did not always lead to hyperglycaemia nor the same level of defective glucose uptake in the insulin-sensitive tissues as may be expected from such an important molecule of glucose metabolism. The different background strains of the models may provide a valid explanation for these variations in phenotype. All these models have been produced on a mixed background with combinations of C57BL6/J, SJL, SV-129, CBA, and CD1 strains with each strain contributing various percentages to the overall background. It is evident from the literature that different strains of mice have inherent genetic differences that could play a significant role on the physiological outcomes of manipulating genes (Andrikopoulos et al. 2005). Thus, it cannot be excluded that such differences in the phenotype of deleting GLUT4 could be attributed to the peculiarity of the background strain. In addition, in vitro studies using isolated muscles from the Glut 4 null mice exhibited different capacities for insulin-stimulated glucose uptake, with soleus muscle demonstrating increased basal glucose uptake in male mice and normal basal and insulin-stimulated uptake in female mice, while extensor digitorum longus (EDL) muscle showed the expected reduced basal and insulin-stimulated glucose uptake (Stenbit et al. 1996).

Little is known about the compensatory mechanisms for the absence of GLUT4, particularly in vivo, that could explain the dissimilarity in glucose uptake patterns (Rossetti et al. 1997, Stenbit et al. 1997, Zisman et al. 2000, Kim et al. 2001, Kaczmarczyk et al. 2003). This effectiveness of compensation is therefore important to understand given that type 2 diabetes is closely associated with impaired glucose uptake. Our study, therefore, was designed to determine the effects of absence of muscle-specific GLUT4 on glucose metabolism on a pure C57B16/J background and to determine whether any compensatory mechanisms exist. Herein, we report that absence of skeletal muscle GLUT4 does not cause any impairment in insulin-stimulated glucose uptake in muscle. Conversely, in the hypertrophied heart, complete GLUT4 ablation leads to significantly reduced glucose uptake. We find that GLUT1 and GLUT12 protein levels were not affected in skeletal muscle and heart tissue of Glut4 KO mice. Our data suggest that GLUT4 deletion does not impact on glucose uptake in the C57B16/J mouse because other as yet unidentified mechanisms compensate for its absence.

\section{Materials and Methods}

\section{Animals}

Muscle-specific Glut4 KO mice were produced using the Cre/loxP system. The construct used for the generation of the mice has been previously reported (Kaczmarczyk et al. 2003). Heterozygous floxed Glut4 mice, with the PGKNeoR selection cassette inserted at the end of exon 11, were made on a C57B16/J background with exons 7-10 targeted for deletion. These mice were mated with the $\alpha$-actin Cre mouse (also on a C57Bl6/J background) that confers deletion specifically in skeletal muscle and heart. Progeny from this mating (heterozygous for Glut 4 and Cre (GLUT4lox + /Cre $+(-))$ were brother-sister mated to obtain non-floxed Glut4 mice with or without Cre (lox $-/-)$ and floxed Glut4 mice with Cre $(\mathrm{lox}+/+\mathrm{Cre}+)$. The former being mice with 100\% GLUT4 expressed in muscles and served as controls and the latter with a complete KO of GLUT4 from muscles. Male and female mice at 11-12 weeks of age were used in this study with the control (lox $-/-)$ littermates to the $\mathrm{KO}(\mathrm{lox}+/+\mathrm{Cre}+)$ mice. The mice were housed in the University of Melbourne, Department of Medicine Animal Research Facility at the Austin Repatriation Hospital. 
Lighting was artificial and timer controlled with a $12 \mathrm{~h}$ light: $12 \mathrm{~h}$ darkness cycle. Room temperature was kept constant at $22{ }^{\circ} \mathrm{C}$. Mice were fed a standard laboratory chow diet and water ad libitum. The standard non-purified chow diet in pelleted form comprised (w/w) 3\% of energy as fat, $77 \%$ of energy as carbohydrate and 20\% of energy as protein and was purchased from Barastock Products (Pakenham, Vic., Australia). For the high-fat (HF)-feeding studies, mice were fed ad libitum a $60 \%$ HF diet for 6 weeks from 6 weeks of age $(60 \%$ of energy as fat, $20 \%$ energy as carbohydrate and $20 \%$ energy as protein), which and was purchased from Specialty Feeds, Glen Forrest, WA, Australia. All animal work was conducted according to relevant national and international guidelines and approved by the Austin Health Animal Ethics Committee (AEC \#A2007/02764). For all glucose metabolism investigations, mice were tested in an anaesthetised state as previously published (Kaczmarczyk et al. 2003, Lamont et al. 2003, 2006, Steinberg et al. 2006, Andrikopoulos et al. 2008, Visinoni et al. 2008, Mangiafico et al. 2011, Wong et al. 2011).

\section{Surgery for basal and hyperinsulinaemic/englycaemic clamp studies}

Mice were provided with $0 \cdot 1 \mathrm{~g}$ food per $1 \cdot 0 \mathrm{~g}$ body weight the previous night at $1700 \mathrm{~h}$ to achieve a fasting period of $\sim 6 \mathrm{~h}$, with free access to water. Body weights were measured before each physiological test at $0800 \mathrm{~h}$, and mice were anaesthetised with an i.p. injection of sodium pentobarbitone at a dose of $100 \mathrm{mg} / \mathrm{kg}$ (Therapon, Burwood, Vic., Australia). Surgery was performed to insert two single lumen polyethylene catheters $(0.30 \mathrm{~mm}$ ID $\times 0.64 \mathrm{~mm} \mathrm{OD})$, one into the right jugular vein for tracer and insulin infusion and the other into the left carotid artery for blood sampling as described previously (Lamont et al. 2006).

\section{Tracer infusions}

For both basal and hyperinsulinaemic/euglycaemic clamps, all mice were infused with an initial 2 min priming dose of radiolabelled glucose tracer $\left[6-{ }^{3} \mathrm{H}\right]$ glucose at a rate of $100 \mu \mathrm{Bq} / \mathrm{min}$ in $0.9 \%$ saline followed by a constant infusion of tracer at a rate of $5.5 \mu \mathrm{Bq} / \mathrm{min}$ in $0.9 \%$ saline for the duration of the experiment. Euglycaemia was maintained using $1 \%$ glucose solution in $0.9 \%$ saline.

\section{Basal turnover, hyperinsulinaemic/euglycaemic clamps and glucose uptake into peripheral tissue}

Basal turnover, hyperinsulinaemic/euglycaemic clamps and peripheral glucose uptake into individual tissues (total quadriceps, total gastrocnemius, heart, diaphragm and white and brown adipose tissues (BAT)) under basal and insulinstimulated conditions were performed in $\mathrm{KO}$ and control mice as described previously (Lamont et al. 2006).

\section{Oral glucose tolerance test}

For the determination of glucose tolerance, an oral glucose tolerance test was performed on 6-h fasted mice, as described previously (Andrikopoulos et al. 2008). In brief, mice were anaesthetised with an i.p. injection of sodium pentobarbitone at a dose of $100 \mathrm{mg} / \mathrm{kg}$ (Therapon) and surgery was performed to insert a carotid catheter. A tracheotomy was performed to aid with breathing. A bolus of glucose $(2 \mathrm{~g} / \mathrm{kg})$ was delivered into the stomach via a gavage needle (20-gauge, $38 \mathrm{~mm}$ long curved with a $2 \frac{1}{4} \mathrm{~mm}$ ball end, Able Scientific, Canning Vale, WA, Australia). Blood (200 $\mu \mathrm{l})$ was sampled at $0,15,30,45,60$ and $120 \mathrm{~min}$ thereafter, centrifuged and stored at $-20^{\circ} \mathrm{C}$ until analyses of plasma glucose and insulin levels. Red blood cells were returned to the mice with equal volumes of heparinised saline between each sample time to prevent anaemic shock.

\section{$R N A$ extraction and real-time PCR}

Total RNA was extracted from white quadriceps, heart and white adipose tissue (WAT) using standard Trizol methodology and its concentration determined by spectrophotometry. RNA $(1 \mu \mathrm{g})$ was reverse transcribed using the RT-PCR Introductory System (Promega). Gene expression was evaluated using real-time PCR analyses using TaqMan gene expression assay primers: Mm00441473_m1 Slc2a1 (Glut1), Mm00436615_m1 Slc2a4 (Glut4) and Mm00619244_m1 Slc2a12 (Glut12) (Applied Biosystems, Life Technologies, Carlsbad, CA, USA). For the housekeeping gene, rRNA was used (18s rRNA 4319413E) (Applied Biosystems, Life Technologies). The PCR mixture contained the primers, the fluorogenic probe mix and the TaqMan Universal PCR Master mix (Applied Biosystems). All amplification reactions were performed in duplicate. Results were analysed with Applied Biosystems 7500 system software. The relative quantification method was used to assess the expression level of the target genes. This analysis uses the $2^{\wedge}\left(-\Delta \Delta C_{\mathrm{t}}\right)$ method, which is based on relative quantification of the $\mathrm{KO}$ mice to the control mice as previously published (Kebede et al. 2008, Visinoni et al. 2008, 2012, Mangiafico et al. 2011, Wong et al. 2011).

\section{Western blotting}

Tissues for GLUT4 expression were homogenised in lysis buffer (20 mM Tris, $1 \mathrm{mM}$ EDTA and 0.25 mM sucrose, $\mathrm{pH} 7 \cdot 4$ ) and ultracentrifuged to obtain the membrane fraction. The amount of protein in the homogenate was determined using the Bio-Rad Protein Assay, based on the Bradford method using Bio-Rad Quick Start BSA standards. Equivalent amounts of protein $(10 \mu \mathrm{g}$ for heart, $30 \mu \mathrm{g}$ for white quadriceps and $30 \mu \mathrm{g}$ for WAT) were resolved on a $12 \%$ SDS-PAGE and electrophoretically transferred (semi-dry) onto a PVDF membrane (Immobilon-P transfer membrane, Millipore, Kilsyth, Vic, Australia). GLUT4 was detected using the Santa Cruz Biotechnology, Inc. (Santa Cruz, CA, USA) Glut4 (C-20) 
primary antibody (1:500 dilution in 5\% BSA in TBS/T) and subsequently probed with the polyclonal rabbit anti-goat immunoglobulins/HRP secondary antibody (1:5000 dilution in 5\% BSA in TBS/T) (Dako Cytomation, Campbellfield, Vic, Australia) and Pierce ECL Western Blotting Substrate. GLUT1 was detected using the monoclonal Glut1 primary antibody from Abcam, Cambridge, MA, USA (1:5000 dilution in 5\% BSA in TBS/T) and subsequently probed with the polyclonal rabbit anti-goat immunoglobulins/HRP secondary antibody (1:5000 dilution in 5\% BSA in TBS/T) (Dako Cytomation) and
Pierce ECL Western Blotting Substrate. Tissues for GLUT12 expression were processed using methods previously described (Rogers et al. 2002, Macheda et al. 2003) and GLUT12 detected using a polyclonal antibody kindly donated by Dr Suzanne Rogers, University of Melbourne, Department of Medicine, St Vincents Hospital, Melbourne. Membranes were exposed to Amersham Hyperfilm (GE Healthcare, Buckinghamshire, UK) and were scanned and quantified using a Bio-Rad gel doc and Quantity One software. India Ink staining was used for the loading control.
A

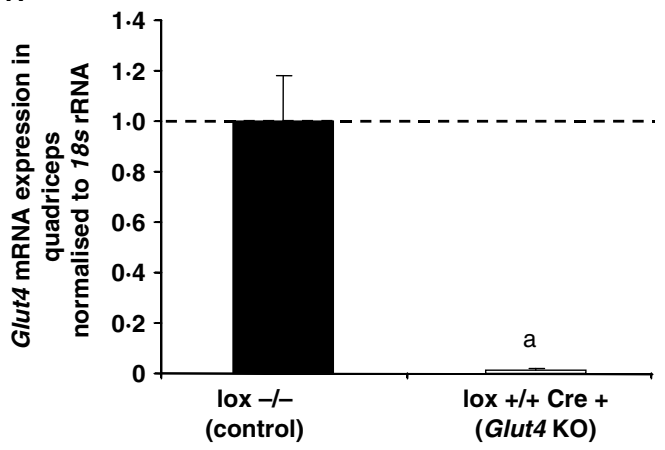

C

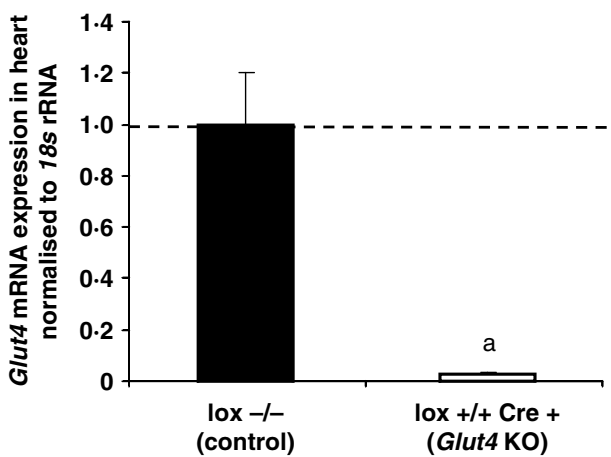

E

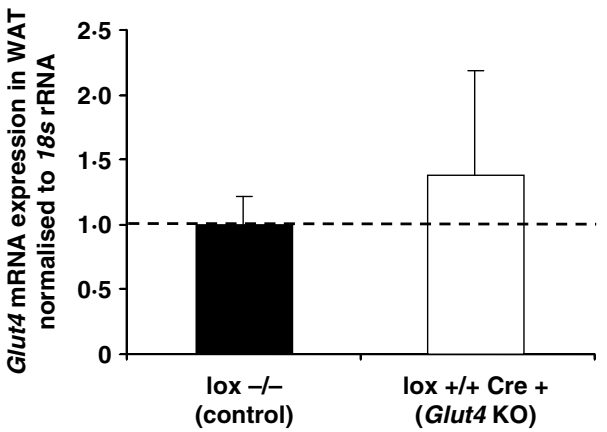

B

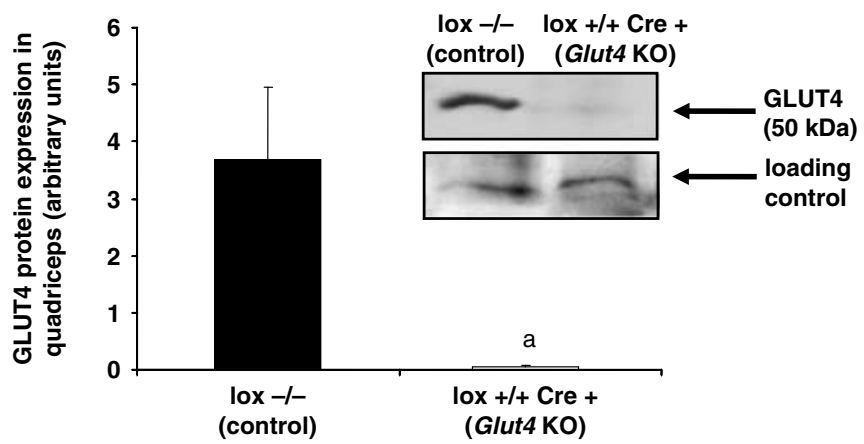

D
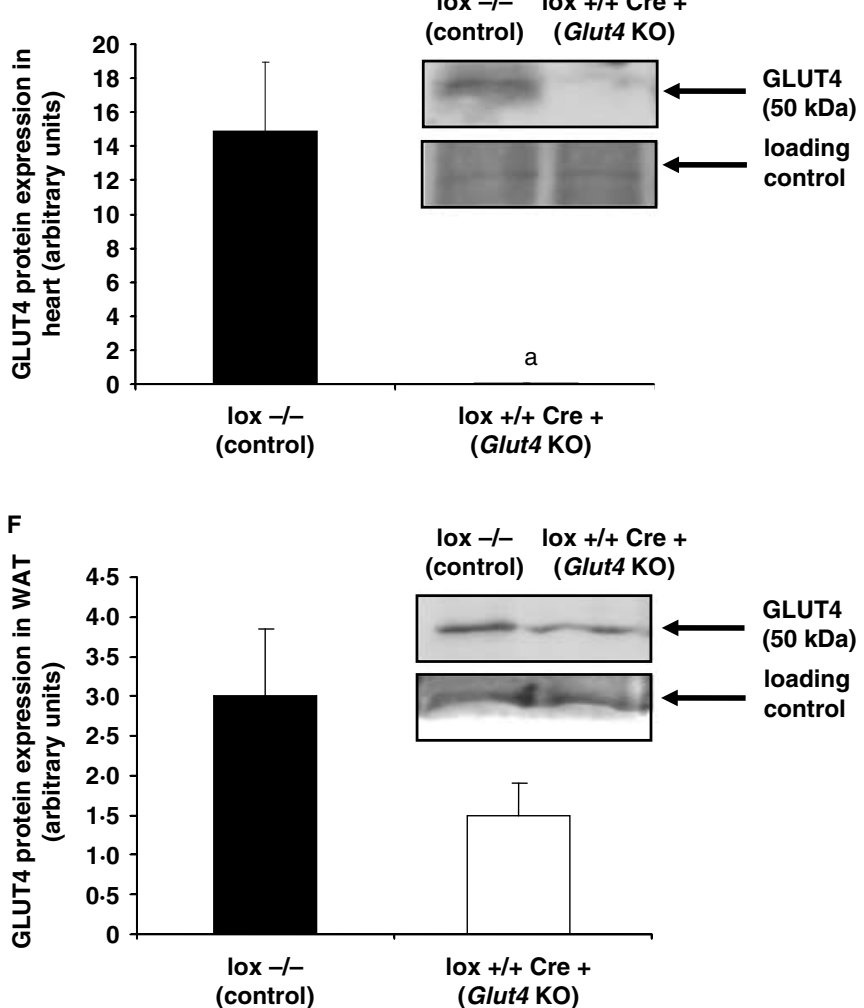

Figure 1 Glut4 mRNA expression levels normalised to $18 \mathrm{~s}$ rRNA housekeeping gene and shown as change from control in quadriceps $(\mathrm{A})$, heart $(\mathrm{C})$ and WAT (E) from control $(\mathrm{lox}-/-$ (black)) and Glut4 KO (lox +/+Cre + (white)) mice at 12 weeks of age. GLUT4 protein expression levels in quadriceps (B), heart (D) and WAT (F) from control (lox $-/-$ (black)) and Glut4 $\mathrm{KO}($ lox $+/+$ Cre + (white)) mice at 12 weeks of age. Data shown are pooled means of both males and females \pm s.E.M. $\left({ }^{\mathrm{a}} P<0 \cdot 05 \mathrm{vs}\right.$ lox $\left.-/-, n=4-8\right)$. 


\section{Statistical analysis}

All data are presented as mean \pm s.E.M. For glucose metabolism parameters, male and female data were pooled as no significant differences were detected between the sexes as measured by ANOVA. Homoeostasis model assessment of insulin resistance (HOMA-IR) was calculated using the formula (fasting glucose $X$ fasting insulin) $/ 22 \cdot 4$ as a surrogate measure of insulin sensitivity as previously validated and published (Andrikopoulos et al. 2008). Comparisons between single parameters measured were made using the two-tailed, unpaired, Student's $t$-test (Excel 2003 for Windows). The trapezoidal rule was used to determine the area under the curve (AUC). For differences between plasma glucose and insulin levels during the glucose tolerance tests, a general linear model ANOVA was used for comparison and a Tukey's post hoc $t$-test to determine significance (Minitab, 2007, Minitab, Inc., Sydney, NSW, Australia). Significance was determined as $P<0 \cdot 05$ for all analyses.

\section{Results}

\section{Glut4 $m$ RNA expression}

To confirm the level of deletion of GLUT4 in our mice, we measured mRNA expression levels in whole quadriceps, cardiac muscle (heart) and WAT of the lox $+/+$ Cre + (Glut 4 $\mathrm{KO})$ and lox $-/-$ control mice. Complete $\mathrm{KO}$ at the level of mRNA was shown in the quadriceps of the Glut4 KO mice compared with the lox $-/-$ (Fig. 1A; $P<0 \cdot 05)$. In heart tissue, there was a very small level of Glut 4 expression in the Glut4 KO mice that was significantly lower compared with the lox $-/-$ mice (Fig. 1C). In WAT, there was no significant difference in Glut4 mRNA expression in the Glut4 KO mice (Fig. 1E).

\section{GLUT4 protein expression}

When protein levels were assessed by western blotting, we found that GLUT4 was significantly reduced in the Glut4 $\mathrm{KO}$ mice (by 99\%) compared with the lox $-/-$ control in the quadriceps (Fig. 1B) and in the heart tissue (Fig. 1D). In the WAT, GLUT4 protein levels were not statistically different between the groups of mice (Fig. 1F).

\section{Physiological assessment of Glut4 KO mice}

Body weights of the Glut4 KO male mice were significantly lower compared with lox $-/-$ controls $(P<0 \cdot 05$, Table 1$)$. When adiposity levels were assessed (Table 1), both gonadal and subcutaneous fat depots were significantly reduced in the Glut4 KO mice compared with the lox $-/-$ control mice. All other fat depots were statistically comparable in mass. A similar body weight phenotype was also observed in female Glut4 KO mice; however, only infra-renal mass was significantly reduced compared with the lox $-/-$ control mice (Table 1). While absolute heart weights were not significantly different between the groups, when corrected for body weight the Glut $4 \mathrm{KO}$ mice exhibited a $23 \%$ increase in heart size compared with the control mice (Table $1, P<0 \cdot 05$ ) which was comparable to that of our previously published study (Kaczmarczyk et al. 2003). As with the male mice, female mice also shared the same cardiac hypertrophy when corrected for body weight (Table 1).

Pooled male and female data surprisingly showed significantly reduced 6-h fasting plasma glucose levels (by $19 \%)$ in the Glut4 KO mice compared with the lox - / control mice (Fig. 2A, $P<0 \cdot 05$ ), while fasting plasma insulin levels (Fig. 2B) were even more reduced (by 75\%) compared with lox $-/-$ mice $(P<0 \cdot 005)$. When HOMA-IR was calculated, the Glut4 $\mathrm{KO}$ mice had significantly reduced values compared with the control mice $(0.90 \pm 0.15$ vs $0 \cdot 2 \pm 0 \cdot 03$; control vs Glut4 KO, $P<0 \cdot 001)$, indicative of increased insulin sensitivity (Andrikopoulos et al. 2008).

\section{Glucose tolerance in Glut4 $\mathrm{KO}$ mice}

Glucose tolerance was not impaired in the Glut4 $\mathrm{KO}$ mice compared with the lox $-/-$ control mice, as shown by the similar glucose excursion pattern (Fig. 3A) and the resulting $\mathrm{AUC}^{\text {glucose }}$ (Fig. 3B). The small rise in plasma glucose levels at

Table 1 Body weight, absolute heart weight, corrected heart weight and adipose tissue mass (subcutaneous, infra-renal, gonadal and brown adipose tissue) in male and female control (lox $-/-)$ and Glut4 $\mathrm{KO}(\mathrm{lox}+/+\mathrm{Cre}+)$ mice

\begin{tabular}{|c|c|c|c|c|}
\hline & \multicolumn{2}{|l|}{ Males } & \multicolumn{2}{|l|}{ Females } \\
\hline Heart weight (g) & $0.143 \pm 0.006$ & $0.153 \pm 0.006$ & $0 \cdot 11 \pm 0.01$ & $0 \cdot 13 \pm 0.01$ \\
\hline Heart weight $(\mathrm{g} / \mathrm{kg})$ & $5 \cdot 43 \pm 0 \cdot 21$ & $6 \cdot 52 \pm 0 \cdot 68^{*}$ & $5 \cdot 39 \pm 0 \cdot 20$ & $7 \cdot 63 \pm 0.64^{*}$ \\
\hline Subcutaneous fat mass ( $\mathrm{g}$ ) & $0 \cdot 110 \pm 0 \cdot 011$ & $0 \cdot 075 \pm 0 \cdot 010^{*}$ & $0 \cdot 09 \pm 0 \cdot 01$ & $0 \cdot 07 \pm 0 \cdot 005$ \\
\hline Infra-renal fat mass (g) & $0 \cdot 030 \pm 0 \cdot 006$ & $0 \cdot 022 \pm 0 \cdot 013$ & $0 \cdot 02 \pm 0 \cdot 003$ & $0 \cdot 01 \pm 0.002 *$ \\
\hline
\end{tabular}

$* P<0 \cdot 05$ vs lox $-/-$. 

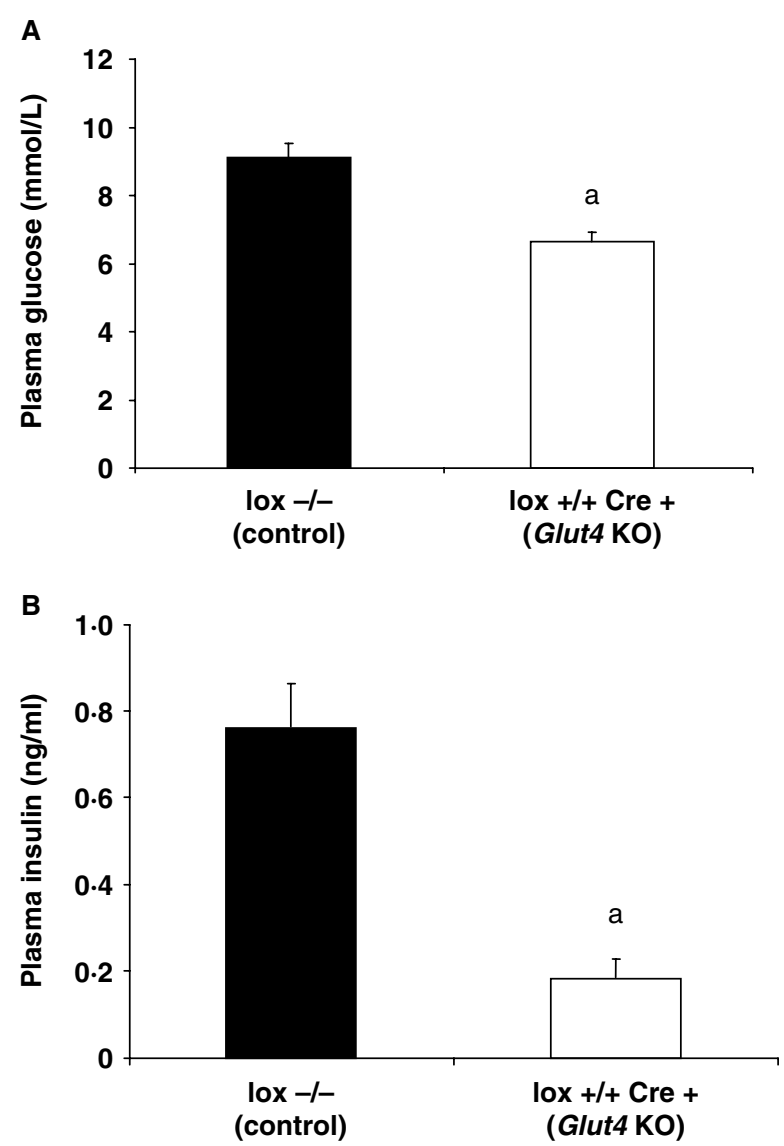

Figure 2 Plasma glucose (A) and plasma insulin (B) following a 6-h fast of control lox $-/$ - (black) and Glut4 $\mathrm{KO}$ (lox +/ + Cre+ (white)) male mice at 12 weeks of age on a standard chow diet. Data shown as mean \pm S.E.M. $\left({ }^{\text {a }} P<0 \cdot 05\right.$ vs lox $\left.-/-, n=11-25\right)$.

15 min post-administration in the control group can be accounted for by the increase in plasma insulin levels at the same time point (Fig. 3C), while in the Glut4 $\mathrm{KO}$ mice the small rise in both plasma insulin and plasma glucose levels suggest increased insulin sensitivity. Overall plasma insulin levels in the Glut4 $\mathrm{KO}$ mice were significantly lower than those in the lox $-/-$ control mice, as reflected by the AUC ${ }^{\text {insulin }}$ (Fig. 3C and D, respectively, $P<0 \cdot 05$ ). This supports the suggestion of enhanced insulin sensitivity and is in agreement with our calculation of HOMA-IR.

\section{Whole-body glucose kinetics of Glut4 KO mice}

When whole-body glucose kinetics was measured under steady-state conditions (Fig. 4A), metabolic clearance rate (MCR) under basal conditions was significantly different between the Glut $4 \mathrm{KO}$ and lox $-/-$ control mice (Table 2, $P<0 \cdot 05)$. Following insulin stimulation (when plasma glucose and plasma insulin levels were matched (Table 2) and steady state achieved (data not shown)), both groups of mice significantly increased their clearance from basal (Table 2,
$P<0 \cdot 05)$ but were not significantly different between the groups. Rate of glucose disappearance ( $\mathrm{Rd}$; Table 2) was similar between the Glut $4 \mathrm{KO}$ mice compared with the controls under both basal and insulin-stimulated conditions. When the glucose infusion rate (GIR) was measured (Table 2), the Glut $4 \mathrm{KO}$ mice had significantly elevated GIR when compared with the lox $-/-$ control mice $(P<0 \cdot 05)$, implying insulin sensitivity though EGP was not different between the two groups of mice (74.58 $\pm 9 \cdot 21$ vs $70 \cdot 66 \pm 9 \cdot 04 \mu \mathrm{mol} / \mathrm{min}$ per $\mathrm{kg}$, lox $-/-$ control vs GLUT4 KO respectively). Together, the data indicate that despite complete deletion of GLUT4 from muscle, both MCR and Rd were not impaired.

\section{Tissue-specific glucose uptake in Glut4 KO mice}

Glucose uptake into both skeletal muscle types (quadriceps (Fig. 4B) and gastrocnemius (Fig. 4C)) was significantly elevated following insulin stimulation from basal levels in both the Glut $4 \mathrm{KO}$ and lox $-/-$ control mice. Under both basal and insulin-stimulated conditions, glucose uptake into these muscle types was comparable between Glut $4 \mathrm{KO}$ and control mice. In heart muscle (Fig. 4D), basal uptake was not significantly different in the Glut4 KO mice compared with the lox $-/-$ control mice, but following insulin stimulation, the Glut4 KO mice did not take up as much glucose as the lox $-/-$ control mice $(P<0 \cdot 05)$, even though the levels were significantly raised from basal $(P<0 \cdot 05)$. With respect to the diaphragm (Fig. 4E), both groups had elevated uptake in response to insulin compared with basal $(P<0 \cdot 05)$ with the Glut4 KO mice demonstrating a greater uptake under basal conditions compared with the lox $-/-$ control mice $(P<0 \cdot 05)$, but not following insulin stimulation. Elevated glucose uptake into adipose tissue showed that both WAT and BAT responded to insulin stimulation compared with basal turnover (Fig. 4F and $\mathrm{G}$ respectively, $P<0 \cdot 05$ ). WAT was similar in the basal state between the Glut $4 \mathrm{KO}$ and lox $-/-$ control mice and was significantly elevated in the $\mathrm{KO}$ mice following insulin stimulation (Fig. $4 \mathrm{~F}, P<0 \cdot 05$ ). BAT demonstrated reduced uptake basally but no difference following insulin stimulation (Fig. 4G). Together, these results suggest that in the absence of muscle GLUT4, there is still considerable ability to transport glucose in both muscle and adipose tissue.

\section{Glut1 and Glut12 mRNA expression in Glut4 KO mice}

Given that the Glut4 KO mice showed normal glucose uptake, there was an inference for a compensatory response from other GLUTs. Therefore, we measured mRNA expression of the other transporters known to be expressed in muscle and fat: Glut1 and Glut12. Figure 5A shows that quadriceps Glut 1 mRNA levels were significantly elevated in the Glut4 KO mice $(P<0.05)$ while Glut12 remained unchanged. When heart tissue expression was measured (Fig. 5B), we surprisingly found no differences in either Glut1 or Glut12 levels in the Glut4 $\mathrm{KO}$ mice compared with the 

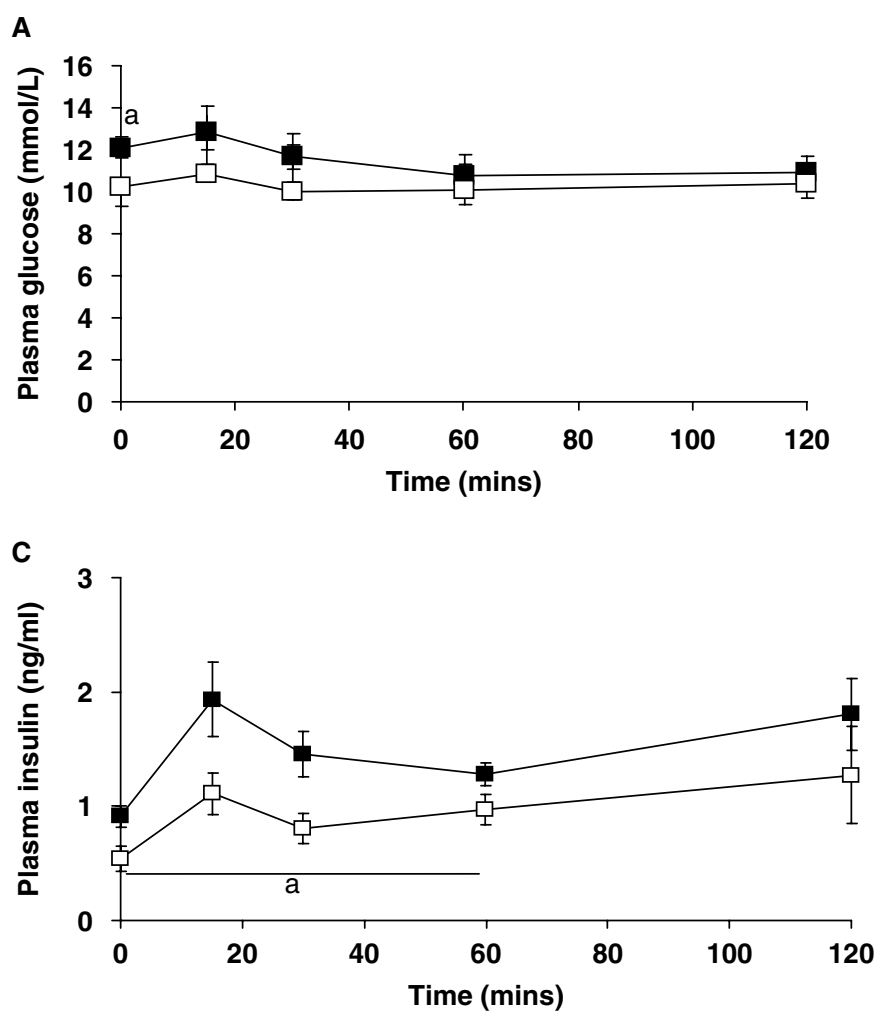

B

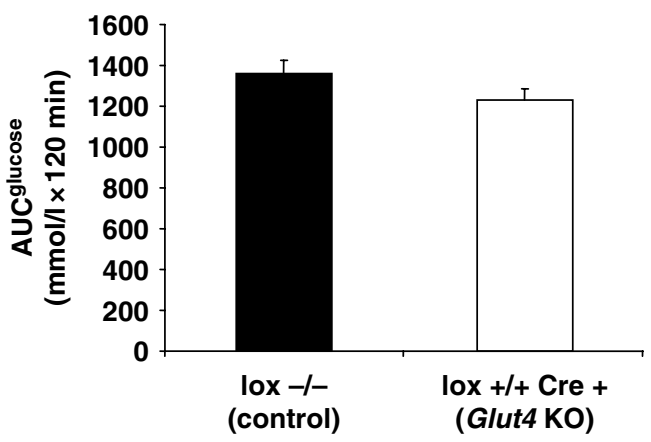

D

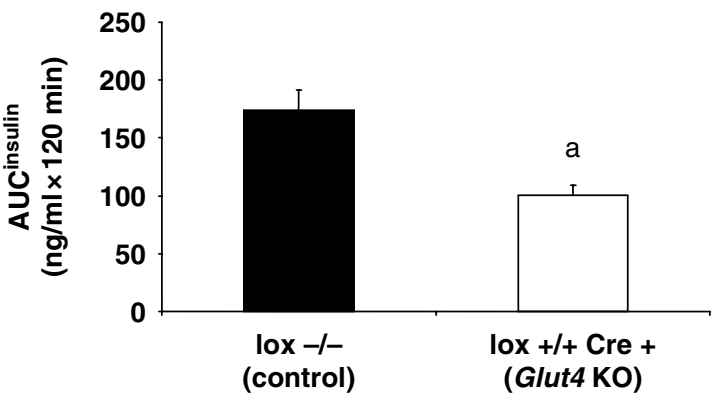

Figure 3 Plasma glucose excursion levels following an OGTT (2 g/kg glucose, $6 \mathrm{~h}$ fast) (A) and the total AUC $C^{\text {glucose }}$ over 120 min (B) from control (lox $-/-$ (black)) and Glut4 KO (lox $+/+$ Cre + (white)) mice at 12 weeks of age. Plasma insulin levels following an OGTT (C) and the total AUC ${ }^{\text {insulin }}$ over 120 min (D) from control (lox - / - (black)) and Glut4 KO (lox +/+Cre+ (white)) mice at 12 weeks of age. Data shown are pooled mean of both males and females \pm s.E.M. $\left({ }^{a} P<0.05\right.$ vs lox $\left.-/-, n=5-14\right)$.

lox $-/-$ control mice. Expression in WAT also showed no differences in either Glut1 or Glut12 levels in the Glut4 KO mice (Fig. 5C). To confirm the mRNA expression data, we performed western blot analysis in both quadriceps and heart. Despite elevated Glut1 mRNA expression, protein expression was not different between the strains in either the quadriceps (Fig. 6A) or the heart tissue (Fig. 6B). Similarly, with GLUT12, there were no differences in the protein levels of this transporter in either the quadriceps (Fig. 6C) or the heart (Fig. 6D).

\section{Glucose tolerance in Glut4 KO mice following HF feeding}

As we found normal glucose tolerance in the Glut4 $\mathrm{KO}$ mice under chow-fed conditions, we wanted to determine whether these mice would be protected against HF-induced glucose intolerance in a separate cohort of mice. Following 6 weeks of HF feeding, Glut4 $\mathrm{KO}$ male mice still weighed significantly less than the lox $-/-$ control mice $(19 \cdot 3 \pm 1 \cdot 1$ vs $22.9 \pm 0.7 \mathrm{~g}$, respectively, $P<0.05)$ with the same pattern seen in the female mice (data not shown). However, WAT mass across all three depots was not significantly different between the two groups. Plasma glucose levels at baseline (pooled male and female data) were not significantly different between HF-fed Glut4 KO and the lox - / - mice (Fig. 7A); however, plasma insulin levels were significantly higher in the Glut4 $\mathrm{KO}$ mice compared with the lox $-/-$ control mice (Fig. 7B, $P<0 \cdot 05)$. When HOMA-IR was calculated, the Glut4 KO mice had significantly higher values compared with the control mice $(0 \cdot 80 \pm 0.08$ vs $0.58 \pm 0 \cdot 07$; Glut $4 \mathrm{KO}$ vs control, $P<0 \cdot 05)$, indicative of reduced insulin sensitivity. During the oral glucose tolerance test (OGTT), the Glut4 $\mathrm{KO}$ mice maintained the same glucose excursion pattern as the lox $-/-$ control mice (Fig. 7C), which was reflected in the similar AUC ${ }^{\text {glucose }}$ (Fig. 7D). Interestingly, when plasma insulin levels were measured during these times, the Glut4 $\mathrm{KO}$ mice displayed increased levels at 60 and $120 \mathrm{~min}$ (Fig. 7E) with an overall significant increase in the total AUC $^{\text {insulin }}$ (Fig. 7F, $P<0 \cdot 05$ ). The data suggest that Glut4 $\mathrm{KO}$ mice were not protected against $\mathrm{HF}-\mathrm{fed}$ induced insulin resistance.

\section{Discussion}

Skeletal muscle insulin resistance is a key characteristic underpinning type 2 diabetes. Reductions in the insulin-stimulated responsiveness of the glucose transporter, 
A

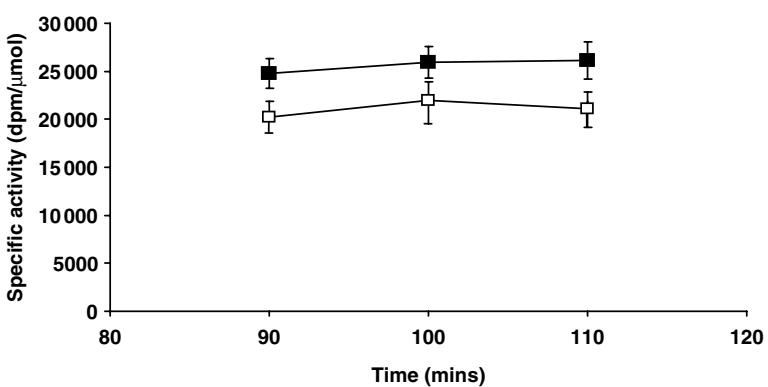

C

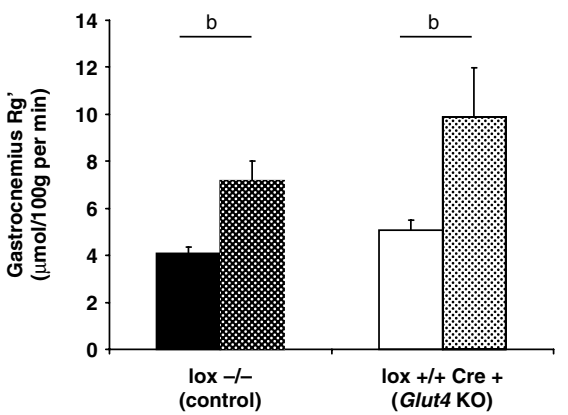

E

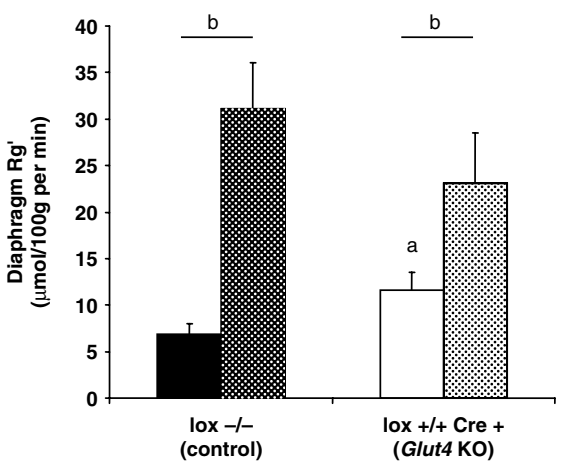

G

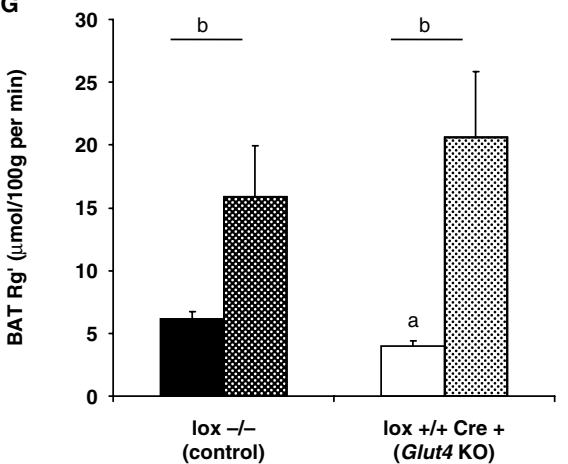

B
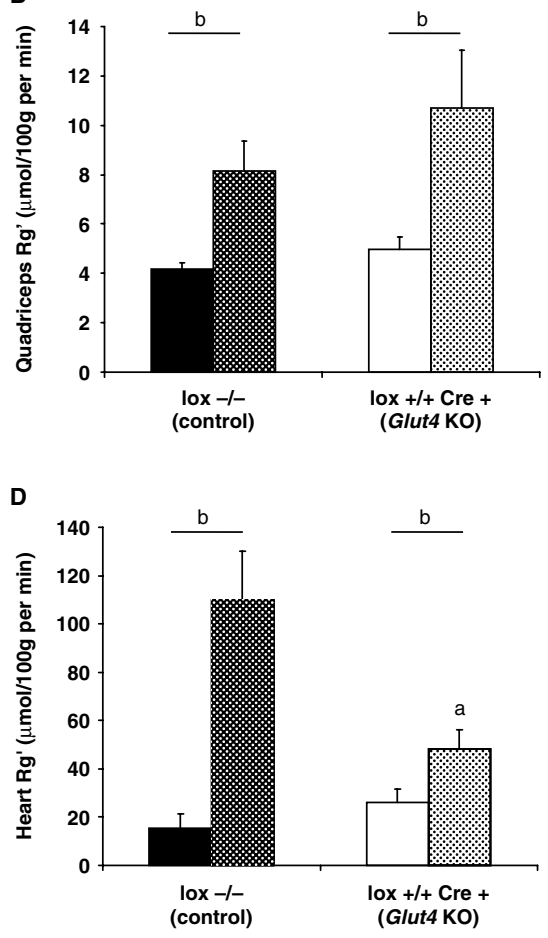

$\mathbf{F}$

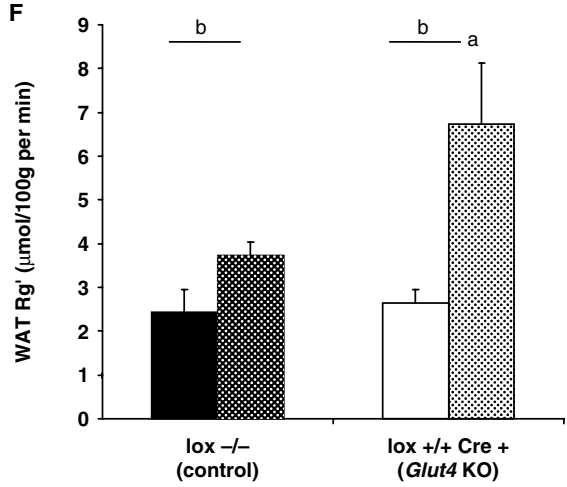

Figure 4 Specific activity (A), glucose uptake $\left(\mathrm{Rg}^{\prime}\right)$ into whole quadriceps (B), whole gastrocnemius (C), heart (D), diaphragm (E), WAT (F) and BAT (G) under 6-h fasted basal (solid bars) and insulin-stimulated (dotted bars) conditions from control (lox $-/-$ (black)) and Glut4 KO (lox $+/+$ Cre + (white)) mice at 12 weeks of age. Data shown are pooled mean of both males and females \pm s.E.M. ( ${ }^{\mathrm{a}} P<0.05$ vs lox $-/-$ and ${ }^{\mathrm{b}} P<0.05$ vs basal uptake, $\left.n=6-10\right)$. 
Table 2 Plasma glucose, plasma insulin and GIR following the hyperinsulinaemic/euglycaemic clamp (insulin-stimulated conditions). MCR and $\mathrm{Rd}$ under basal and insulin-stimulated conditions in control (lox $-/-$ ) and Glut4 KO (lox $+/+$ Cre + ) mice

\begin{tabular}{|c|c|c|c|c|}
\hline & \multicolumn{2}{|l|}{ Basal } & \multicolumn{2}{|c|}{ Insulin stimulated } \\
\hline & lox $-/-(n=8)$ & lox $+/+$ Cre $+(n=10)$ & lox $-/-(n=9)$ & $\mathrm{lox}+/+$ Cre $+(n=10)$ \\
\hline Clamp plasma glucose $(\mathrm{mmol} / \mathrm{l})$ & - & - & $7 \cdot 11 \pm 0 \cdot 50$ & $6 \cdot 09 \pm 0 \cdot 45$ \\
\hline Clamp plasma insulin (ng/ml) & - & - & $3 \cdot 20 \pm 1 \cdot 03$ & $4 \cdot 03 \pm 1 \cdot 14$ \\
\hline Clamp GIR $(\mu \mathrm{mol} / \mathrm{min}$ per kg) & - & - & $17 \cdot 02 \pm 3 \cdot 68$ & $39 \cdot 73 \pm 7 \cdot 06^{*}$ \\
\hline $\mathrm{MCR}(\mathrm{ml} / \mathrm{min}$ per $\mathrm{kg})$ & $9 \cdot 62 \pm 0 \cdot 78$ & $14 \cdot 18 \pm 0 \cdot 97^{*}$ & $19 \cdot 25 \pm 5 \cdot 34^{\dagger}$ & $21 \cdot 01 \pm 1.97^{+}$ \\
\hline $\mathrm{Rd}(\mu \mathrm{mol} / \mathrm{min}$ per $\mathrm{kg})$ & $74 \cdot 77 \pm 7 \cdot 17$ & $87 \cdot 20 \pm 2 \cdot 39$ & $96 \cdot 69 \pm 6 \cdot 25^{\dagger}$ & $110 \cdot 37 \pm 8 \cdot 13^{+}$ \\
\hline
\end{tabular}

$* P<0 \cdot 05$ vs lox $-/-$ and ${ }^{\dagger} P<0 \cdot 05$ vs basal.

GLUT4, is synonymous with a reduced ability for adequate glucose disposal. We have shown that complete deletion of GLUT4 protein from skeletal muscle using Cre-recombinase under the control of the $\alpha$-actin promoter was associated with normal basal and insulin-stimulated glucose uptake in this tissue and normal glucose tolerance. This surprising result indeed opposes what is currently known about GLUT4 deficiency and impaired glucose uptake (Zisman et al. 2000, Kim et al. 2001, Kaczmarczyk et al. 2003). However, our finding of an upregulation of Glut1 mRNA but not GLUT12 in the quadriceps of the $\mathrm{KO}$ mice suggests that this phenomenon is real and that other GLUTs compensate for the absence of GLUT4 in skeletal muscle. Interestingly, in heart, glucose uptake was attenuated in the complete absence of GLUT4 which may be due to the lack of compensation from other GLUTs. Our results therefore suggest that normal glucose uptake specifically in skeletal muscle can still occur in the absence of GLUT4 and that compensation from other unidentified GLUT(s) may be the driving mechanism.

Absence of GLUT4 affected both fasting plasma glucose and plasma insulin levels, with our KO mice clearly exhibiting reduced levels of both compared with control mice that express $100 \%$ GLUT4. This is in contrast to the increased plasma levels demonstrated in earlier muscle Glut4 KO mouse models (Zisman et al. 2000, Kim et al. 2001, Kaczmarczyk et al. 2003) and may be due to the differences in background strain on which our $\mathrm{KO}$ mice are bred and the duration of fasting used before experiments were performed. Our previous Glut4 $\mathrm{KO}$ mice were on a mixed background $(56 \cdot 25 \% \quad \mathrm{C} 57 \mathrm{~B} 16 / \mathrm{J}, \quad 37 \cdot 5 \% \quad 129 \mathrm{~Sv}$ and $6 \cdot 25 \% \mathrm{CBA}$ (Kaczmarczyk et al. 2003)) and were compared to pure C57B16/J wild-type mice. Similarly, the studies by Zisman et al. (2000) and Kim et al. (2001) generated KO and wildtype mice that were on a mixed $129 \mathrm{~Sv}$ and C57Bl6/J background. Our current mice are on the pure isogenic C57Bl6/J background. With the use of such mixed backgrounds, it is impossible to determine the amount that each of the strains is contributing to the overall phenotype (Funkat et al. 2004, Andrikopoulos et al. 2005, Wong et al. 2010), whether it was due to the SV129 genes or C57Bl6/J genes or to an equal contribution from both strains. In addition, we (Andrikopoulos et al. 2008) and others (Dohm 2002) have shown that the duration of fasting can have a significant effect on glucose tolerance and insulin sensitivity in the mouse. In the previous studies, overnight fasting was employed before physiological assessment was performed (Zisman et al. 2000, Kim et al. 2001, Kaczmarczyk et al. 2003), while in the current study, we fasted the mice for $6 \mathrm{~h}$. The longer duration of fasting has been shown to increase insulin sensitivity (Dohm 2002, Andrikopoulos et al. 2008) and may likely exaggerate differences in insulin sensitivity between Glut4 $\mathrm{KO}$ and control mice that were seen previously. These critical differences between the studies are reasons why we pursued this work. The reduced levels of plasma glucose and plasma insulin suggest that the $\mathrm{KO}$ mice may in fact be sensitive to insulin. HOMA-IR calculations, which have previously been validated as an appropriate marker for insulin sensitivity in the mouse (Andrikopoulos et al. 2008), in fact showed a significant reduction in the $\mathrm{KO}$ mice compared with control mice. Hyperinsulinaemic/euglycaemic clamps confirmed this enhanced sensitivity with the GIR higher in the $\mathrm{KO}$ mice leading to the same level of suppression of endogenous glucose production as the control mice. As a result of this increased sensitivity, the plasma insulin excursion during the glucose tolerance test was lower in the $\mathrm{KO}$ mice. Our results therefore clearly show that a lack of muscle-specific GLUT4 does not perturb glucose homoeostasis as would have been expected and previously reported (Zisman et al. 2000, Kim et al. 2001, Kaczmarczyk et al. 2003). Some would suggest that the differences in the Cre mouse used may have contributed to the effects (MCK-Cre used in the Kim et al. and Zisman et al. studies (Zisman et al. 2000, Kim et al. 2001) and $\boldsymbol{\alpha}$-actin Cre used by our laboratory (Kaczmarczyk et al. 2003)). However, our current results demonstrate that this is not the case given we used the same Cre line in both studies from our laboratory. These intriguing results therefore support our argument that the background strain and duration of fasting together play critical roles in the way the body metabolises glucose. The finding that the $\mathrm{KO}$ mice are significantly lighter and have less subcutaneous and gonadal fat mass may be a possible contribution to this sensitivity. The previous musclespecific KO model showed normal body weight and adiposity levels despite altered glucose metabolism (Zisman et al. 2000, Kim et al. 2001, Kaczmarczyk et al. 2003). Interestingly, this 
A

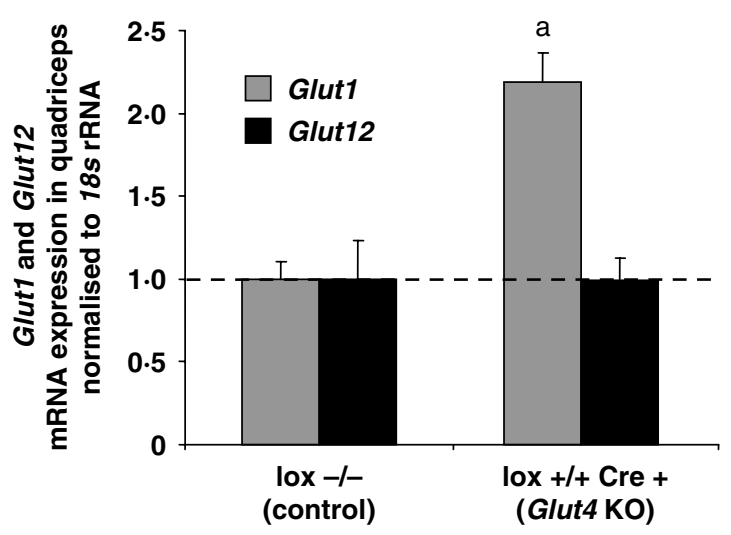

B

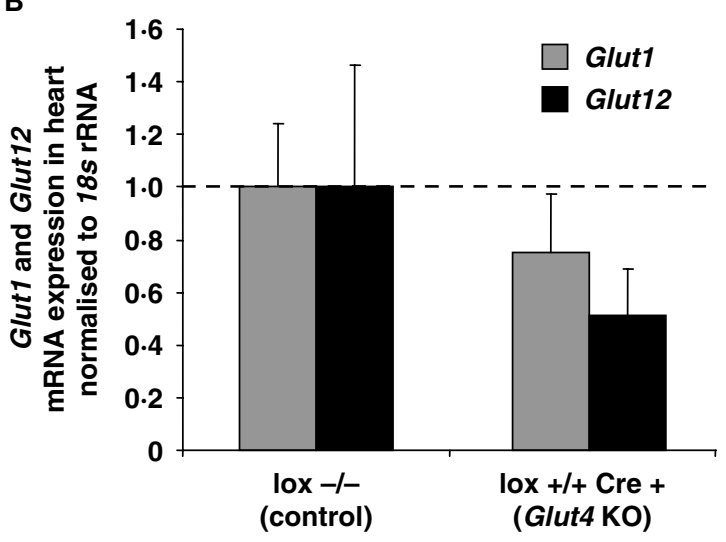

C

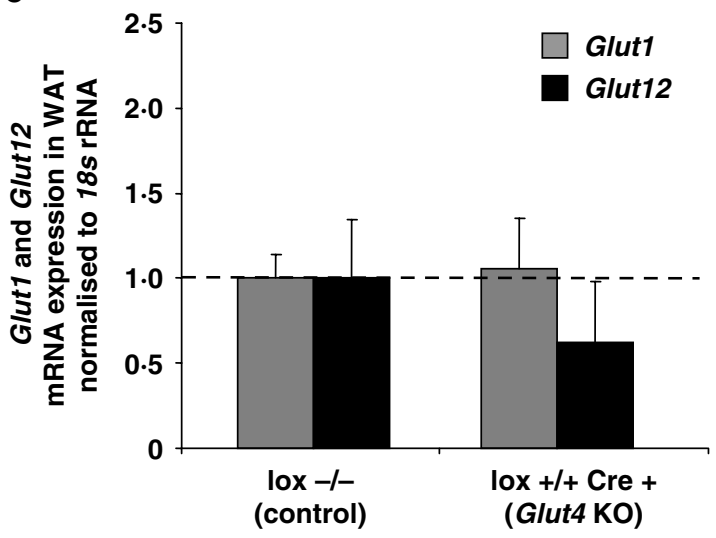

Figure 5 mRNA expression levels of Glut1 (gray bars) and Glut12 (black bars) in whole quadriceps (A), heart (B) and WAT (C) from control (lox -/ - (black)) and Glut4 KO (lox +/ + Cre+ (white)) mice at 12 weeks of age. Expression shown as normalised to $18 \mathrm{~s}$ rRNA housekeeping gene and shown as change from control. Data are pooled mean of both males and females \pm S.E.M. $\left({ }^{\mathrm{a}} P<0.05\right.$ vs lox $\left.-/-, n=4\right)$. lean phenotype was reported in mice with a global deletion of GLUT4 (Katz et al. 1995, Fueger et al. 2007). The mechanisms for this reduced body weight in our KO model are not known and may be due to differences in food intake or physical activity levels or a reduction in lean body mass.

Our results indicated that deletion of GLUT4 did not alter the MCR and that the KO mice behaved similarly to insulin stimulation as the control mice. This was reflected in the ability of the mice to effectively dispose of glucose both basally and in response to insulin into quadriceps and gastrocnemius muscle, like that of the control mice. Surprisingly, while there were similar levels of basal glucose uptake in the hearts of the $\mathrm{KO}$ mice, insulin stimulation was not as marked compared with the control mice. Furthermore, uptake into WAT was clearly augmented in response to insulin in the $\mathrm{KO}$ mice. This increased disposal of glucose into adipose tissue has been previously reported in muscle-specific Glut $4 \mathrm{KO}$ mice (Kim et al. 2001) with reduced glucose uptake into muscle and was suggested as a compensatory response to this muscle defect. However, our previous study showed no difference in glucose uptake into fat (Kaczmarczyk et al. 2003) despite the attenuated muscle glucose uptake. The lower body weight and adipose tissue mass in our current $\mathrm{KO}$ mice likely contributes to this improved sensitivity perhaps through direct action on the adipose tissue or via its effects on improving whole-body insulin sensitivity (reduced basal plasma glucose and plasma insulin, increased GIR, normal MCR and Rd). It is very likely that the marked differences in background strain of the $\mathrm{KO}$ and wild-type control mice and the duration of fasting (overnight vs $6 \mathrm{~h}$ ) from the previous studies and our study will influence the way the mice handle glucose uptake in muscle and fat in response to insulin. Together, our data strongly imply that other GLUTs may be compensating for the deletion in GLUT4 in order to maintain normal glucose homoeostasis and protect the mice from hyperglycaemia. It also appears that this may be tissue specific given that the muscles maintained normality while the heart exhibited reduced transport ability.

To this end, we investigated two of the transporters known to be expressed in insulin-responsive tissues: GLUT1 and GLUT12. GLUT1 is classically thought to be predominantly involved in basal glucose uptake (Marshall et al. 1993, Robinson et al. 1993, Ciaraldi et al. 2005) in heart muscle (Carruthers et al. 2009), skeletal muscle (Marette et al. 1992, Kraegen et al. 1993, Handberg et al. 1994, Ciaraldi et al. 2005) and adipose tissue (Kahn 1994). There has also been evidence suggesting that GLUT1 is insulin regulatable, like GLUT4 (Koivisto et al. 1991, Wilson et al. 1995, Laybutt et al. 1997). We found Glut 1 mRNA levels to be significantly increased in the quadriceps of the $\mathrm{KO}$ mice but were not different in either the heart or the fat tissue to that of the control mice. This appears consistent with our results of normal basal glucose uptake in quadriceps and suggests that in the heart and fat, there is no requirement for more GLUT1 to maintain normal basal glucose uptake. GLUT12, which has been viewed as a second insulin-sensitive glucose transport system due to its 
A

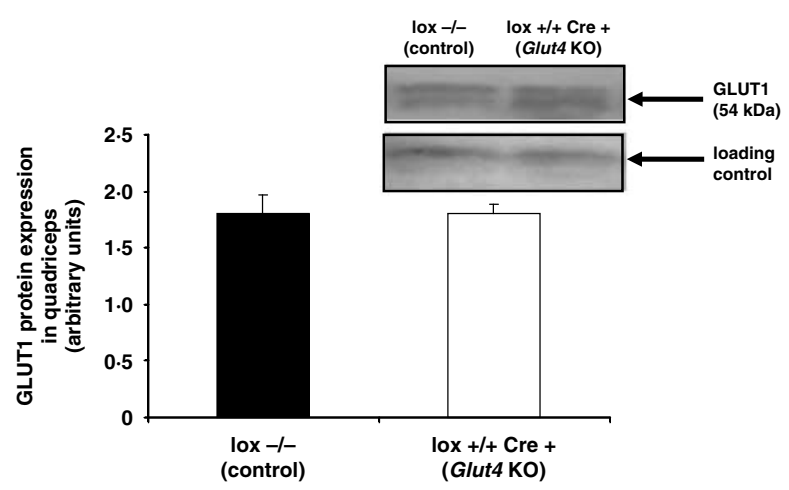

C

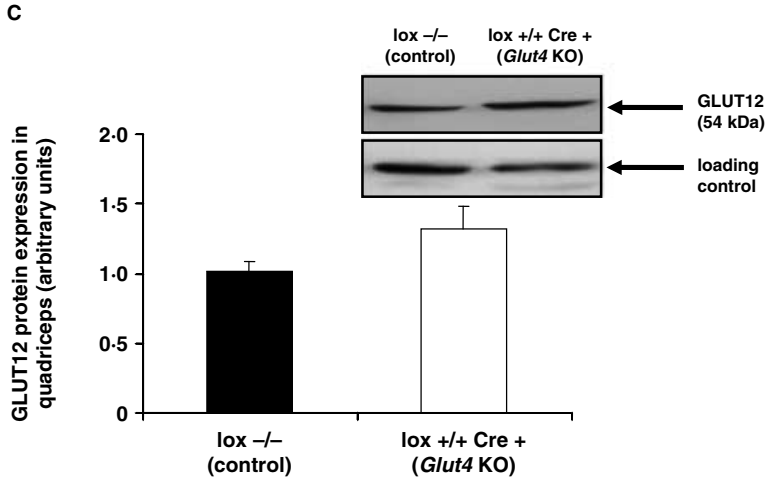

B

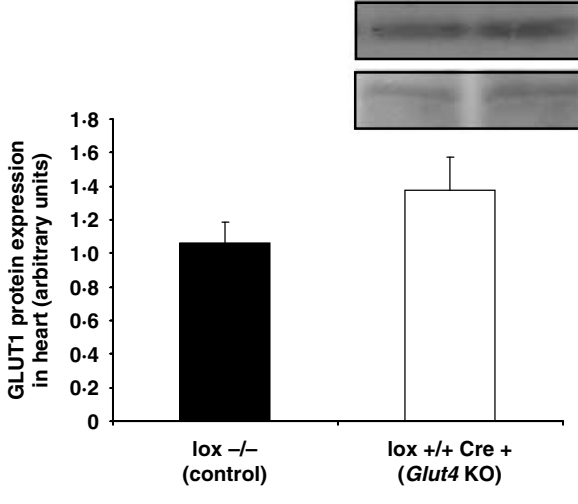

D

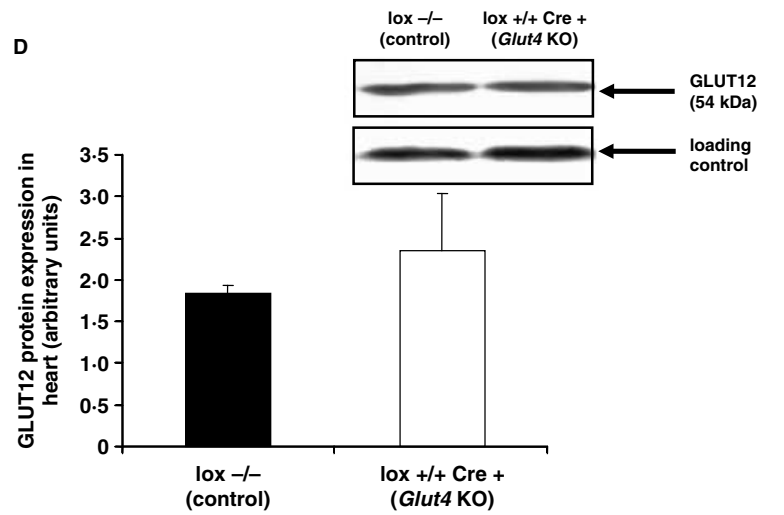

Figure 6 GLUT1 protein expression levels in whole quadriceps (A) and heart (B) from control (lox - / - (black)) and Glut4 KO $($ lox $+/+$ Cre + (white)) mice at 12 weeks of age. GLUT12 protein expression levels in whole quadriceps (C) and heart (D) from control $($ lox $-/-($ black $))$ and Glut4 KO (lox $+/+$ Cre $+($ white $))$ mice at 12 weeks of age. Data shown are pooled mean of both males and females \pm S.E.M. $(n=4)$.

close homology and translocation activities with GLUT4 (Rogers et al. 2002, Stuart et al. 2009, Purcell et al. 2011), was expected to be elevated in the quadriceps of the KO mice and thus explains the normal insulin-stimulated glucose uptake. However, GLUT12 levels did not increase at either the gene or protein level. It is possible that as we measured this protein in whole tissue homogenate, there may be an increase in the translocation efficiency of GLUT12 from the cytoplasm to the surface, that with our current technique we could not capture. Furthermore, we also cannot discount the possibility of the presence of other unidentified GLUTs that may contribute to these observations. Previous studies using isolated muscle tissue (EDL and soleus) from GLUT4 null mice demonstrated different glucose uptake capacities under basal and insulin-stimulated conditions (Stenbit et al. 1996). The study by Stenbit et al. (1996) clearly demonstrated, in vitro, glucose uptake both basally and following insulin stimulation in soleus muscle from the null mice compared with the control mice with EDL showing the expected impaired glucose uptake. The authors concluded that unknown novel GLUTs may be specifically expressed in the soleus muscle of the Glut4 null mice to elicit these effects.
Moreover, a study by Ryder et al. further demonstrated a dose-dependent inhibition of glucose transport activity in soleus muscle from Glut4 null mice through cytochalasin B in vitro. While we did not directly measure glucose uptake in vitro in these specific muscle types from our $\mathrm{KO}$ mice, the evidence presented by these earlier studies support our idea of the existence of novel GLUT4-independent transporter system(s) (Ryder et al. 1999a, Charron et al. 2005). However, neither these early studies nor our own have identified these potential transporters. Whatever the explanation, the results clearly show that alternative GLUTs or increased activation of the existing transporters may be involved in maintaining normal glucose disposal in the muscles of our Glut4-deficient mice.

To our knowledge, there have been no specific studies performed to assess the impact of feeding a HF diet to mice deficient in GLUT4, either at a whole-body level or specifically in the muscle. Given that our results demonstrated normal glucose tolerance under normal chow-fed conditions, we sought to examine what the overall effects of such a diet would be in our mice; would the $\mathrm{KO}$ mice maintain normal glucose tolerance or succumb to the deleterious effects of the 


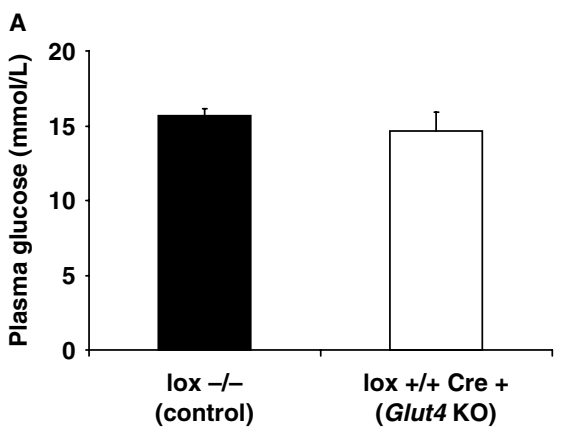

C

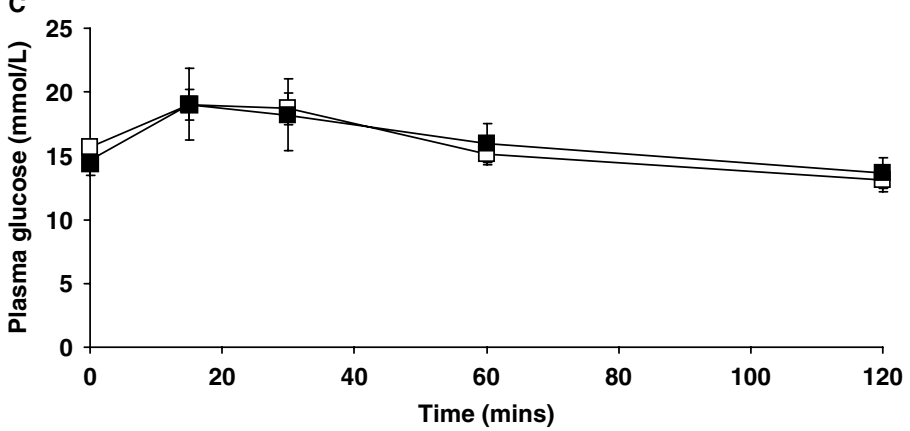

E

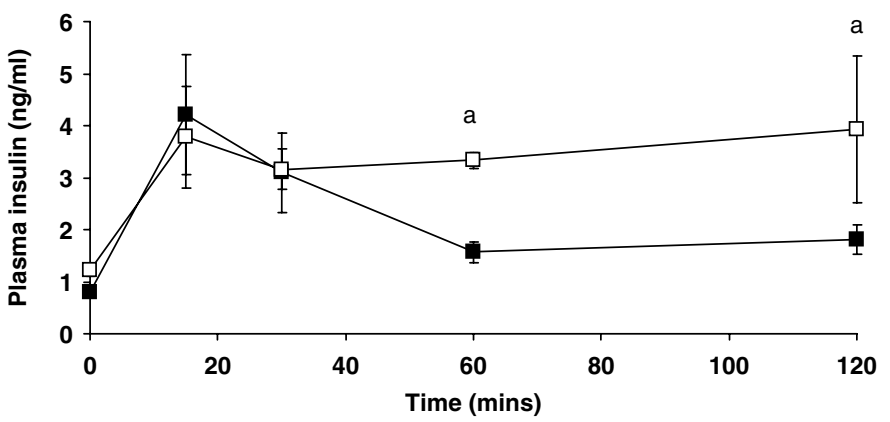

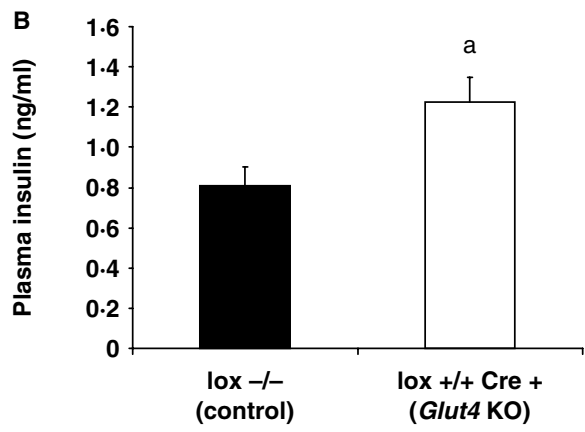

D

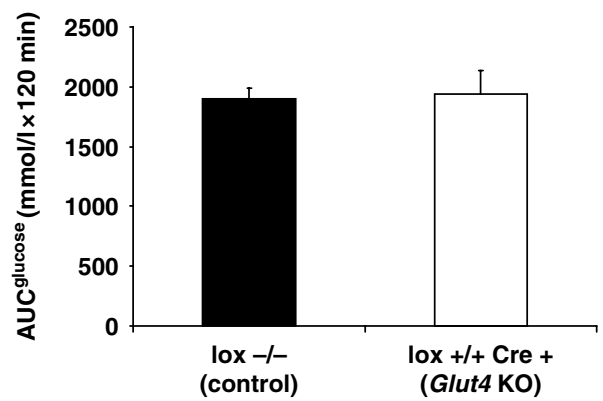

F

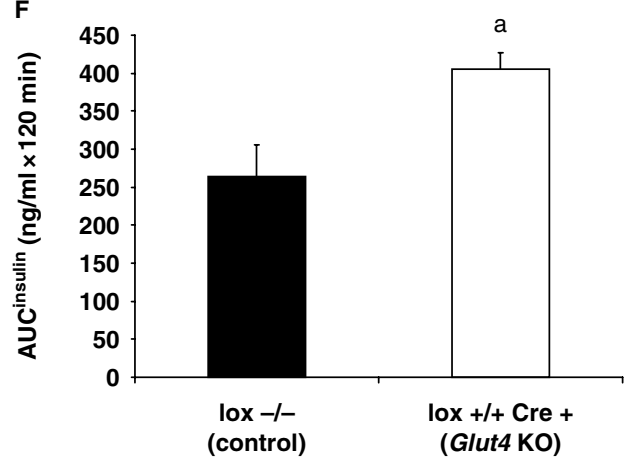

Figure 7 Plasma glucose (A) and plasma insulin (B) following a 6-h fast in mice fed a HF diet for 6 weeks from 6 weeks of age (12 weeks of age). Plasma glucose excursion levels following an OGTT (2 g/kg glucose, 6 - $\mathrm{h}$ fast) (C) and the total AUC ${ }^{\text {glucose }}$ over 120 min (D) from control (lox $-/-$ (black)) and Glut4 KO (lox $+/+$ Cre + (white)) mice fed a HF diet for 6 weeks from 6 weeks of age (12 weeks of age). Plasma insulin levels following an OGTT (E) and the total AUC insulin over 120 min (F) from control (lox-/- (black)) and Glut4 KO $($ lox $+/+$ Cre + (white)) mice fed a HF diet for 6 weeks from 6 weeks of age (12 weeks of age). Data shown are pooled means of both males and females \pm S.E.M. $\left({ }^{a} P<0 \cdot 05\right.$ vs lox $\left.-/-, n=5-12\right)$.

diet? Our work is the first to show that exposure to a HF diet for 6 weeks does not worsen glucose tolerance in the Glut4 $\mathrm{KO}$ mice compared with control mice. In fact, the KO mice had higher plasma insulin levels during the OGTT that contributed to the maintenance of normal glucose tolerance. Therefore, our results demonstrate that following a $\mathrm{HF}$ diet, the $\mathrm{KO}$ mice hypersecreted insulin to maintain the same level of glucose as that of the control mice, indicative of insulin resistance.

Exercise-induced glucose uptake into skeletal muscle is primarily dependent on the amount of GLUT4 present and its ability to translocate to the cell surface in response to muscle contraction (Dohm 2002). While our study showed unimpaired whole-body glucose metabolism in anaesthetised Glut4 KO mice compared to their littermate controls on a chow diet using different approaches, we do not know what effects deleting GLUT4 from the muscle has on exercise-induced glucose disposal in our $\mathrm{KO}$ mice. The use of anaesthesia is indeed a limitation in this assessment and we could speculate that lacking GLUT4 may have a profound effect on glucose uptake given that our HF-feeding studies highlight that stressing the system in the $\mathrm{KO}$ mice can 
promote insulin resistance. To properly determine whether this is the case, glucose uptake in the conscious Glut $4 \mathrm{KO}$ and littermate controls needs to be tested.

We can conclude from our study that deletion of muscle GLUT4 on the pure C57BL6/J background strain resulted in normal whole-body glucose disposal and tolerance and is in contrast to previous studies using a mixed strain background. We (in conjunction with others) speculate that given the normal protein levels of GLUT1 and GLUT12, other unidentified GLUTs are increased (or their intrinsic activity is enhanced) to compensate for the lack of GLUT4 and contribute to the unperturbed glucose homoeostasis.

\section{Declaration of interest}

The authors declare that there is no conflict of interest that could be perceived as prejudicing the impartiality of the research reported.

\section{Funding}

This research did not receive any specific grant from any funding agency in the public, commercial or not-for-profit sector.

\section{Author contribution statement}

B C F conceptualised, designed and co-directed the studies; provided training and supervision for the animal physiology work; collated, interpreted and statistically analysed the data; and wrote and critically revised the manuscript. L J R performed the physiological assessment, whole-body glucose kinetics, glucose uptake and oral glucose tolerance tests; acquired data; and provided critical revision of the manuscript. R S performed the sample and tissue processing for basal turnover and the hyperinsulinaemic clamp, performed the insulin RIA and plasma glucose analysis for all physiological procedures and provided input into the manuscript. Z R performed all the mRNA expression analyses and western blot analyses and provided critical revision of the manuscript. J P provided funding and contributed to the study concept and design and provided critical revision of the manuscript for intellectual content; S A performed the surgeries, co-directed the study, contributed to the study concept and design and interpretation of the data and provided critical revision of the manuscript for intellectual content.

\section{Acknowledgements}

The authors would like to acknowledge Christian Rantzau and Amy Blair for excellent technical assistance and Dr Suzanne Rogers (The University of Melbourne, Department of Medicine, St Vincent's Hospital) for her kind gift of the GLUT12 antibody.

\section{References}

Andrikopoulos S, Massa CM, Aston-Mourney K, Funkat A, Fam BC, Hull RL, Kahn SE \& Proietto J 2005 Differential effect of inbred mouse strain $(\mathrm{C} 57 \mathrm{BL} / 6, \mathrm{DBA} / 2,129 \mathrm{~T} 2)$ on insulin secretory function in response to a high fat diet. Journal of Endocrinology 187 45-53. (doi:10.1677/joe.1.06333)

Andrikopoulos S, Blair AR, Deluca N, Fam BC \& Proietto J 2008 Evaluating the glucose tolerance test in mice. American Journal of Physiology. Endocrinology and Metabolism 295 E1323-E1332. (doi:10.1152/ajpendo. 90617.2008)
Bressler P, Bailey SR, Matsuda M \& DeFronzo RA 1996 Insulin resistance and coronary artery disease. Diabetologia 39 1345-1350. (doi:10.1007/ s001250050581)

Carruthers A, DeZutter J, Ganguly A \& Devaskar SU 2009 Will the original glucose transporter isoform please stand up!. American Journal of Physiology. Endocrinology and Metabolism 297 E836-E848. (doi:10.1152/ajpendo.00496. 2009)

Charron MJ, Gorovits N, Laidlaw JS, Ranalletta M \& Katz EB 2005 Use of GLUT-4 null mice to study skeletal muscle glucose uptake. Clinical and Experimental Pharmacology \& Physiology 32 308-313. (doi:10.1111/ j.1440-1681.2005.04189.x)

Ciaraldi TP, Mudaliar S, Barzin A, Macievic JA, Edelman SV, Park KS \& Henry RR 2005 Skeletal muscle GLUT1 transporter protein expression and basal leg glucose uptake are reduced in type 2 diabetes. Journal of Clinical Endocrinology and Metabolism 90 352-358. (doi:10.1210/jc.2004-0516)

DeFronzo RA, Jacot E, Jequier E, Maeder E, Wahren J \& Felber JP 1981 The effect of insulin on the disposal of intravenous glucose. Results from indirect calorimetry and hepatic and femoral venous catheterization. Diabetes 30 1000-1007. (doi:10.2337/diab.30.12.1000)

DeFronzo RA, Bonadonna RC \& Ferrannini E 1992 Pathogenesis of NIDDM. A balanced overview. Diabetes Care 15 318-368. (doi:10.2337/ diacare.15.3.318)

Dohm GL 2002 Invited review: regulation of skeletal muscle GLUT-4 expression by exercise. Journal of Applied Physiology 93 782-787. (doi:10.1152/japplphysiol.01266.2001)

Ferrannini E, Buzzigoli G, Bonadonna R, Giorico MA, Oleggini M, Graziadei L, Pedrinelli R, Brandi L \& Bevilacqua S 1987 Insulin resistance in essential hypertension. New England Journal of Medicine 317 350-357. (doi:10.1056/NEJM198708063170605)

Ferrannini E, Gastaldelli A, Matsuda M, Miyazaki Y, Pettiti M, Glass L \& DeFronzo RA 2003 Influence of ethnicity and familial diabetes on glucose tolerance and insulin action: a physiological analysis. Journal of Clinical Endocrinology and Metabolism 88 3251-3257. (doi:10.1210/jc.2002-021864)

Fueger PT, Li CY, Ayala JE, Shearer J, Bracy DP, Charron MJ, Rottman JN \& Wasserman DH 2007 Glucose kinetics and exercise tolerance in mice lacking the GLUT4 glucose transporter. Journal of Physiology 582 801-812. (doi:10.1113/jphysiol.2007.132902)

Funkat A, Massa CM, Jovanovska V, Proietto J \& Andrikopoulos S 2004 Metabolic adaptations of three inbred strains of mice (C57BL/6, $\mathrm{DBA} / 2$, and 129T2) in response to a high-fat diet. Journal of Nutrition 134 3264-3269.

Ginsberg H, Kimmerling G, Olefsky JM \& Reaven GM 1975 Demonstration of insulin resistance in untreated adult onset diabetic subjects with fasting hyperglycemia. Journal of Clinical Investigation 55 454-461. (doi:10.1172/ JCI107951)

Graham TE \& Kahn BB 2007 Tissue-specific alterations of glucose transport and molecular mechanisms of intertissue communication in obesity and type 2 diabetes. Hormone and Metabolic Research 39 717-721. (doi:10.1055/ s-2007-985879)

Gulli G, Ferrannini E, Stern M, Haffner S \& DeFronzo RA 1992 The metabolic profile of NIDDM is fully established in glucose-tolerant offspring of two Mexican-American NIDDM parents. Diabetes 41 1575-1586. (doi:10.2337/diabetes.41.12.1575)

Handberg A, Kayser L, Hoyer PE, Micheelsen J \& Vinten J 1994 Elevated GLUT 1 level in crude muscle membranes from diabetic Zucker rats despite a normal GLUT 1 level in perineurial sheaths. Diabetologia 37 443-448. (doi:10.1007/s001250050130)

Hanpeter D \& James DE 1995 Characterization of the intracellular GLUT-4 compartment. Molecular Membrane Biology 12 263-269. (doi:10.3109/ 09687689509072426)

James DE \& Piper RC 1994 Insulin resistance, diabetes, and the insulinregulated trafficking of GLUT-4. Journal of Cell Biology 126 1123-1126. (doi:10.1083/jcb.126.5.1123)

James DE, Piper RC \& Slot JW 1994 Insulin stimulation of GLUT-4 translocation: a model for regulated recycling. Trends in Cell Biology 4 120-126. (doi:10.1016/0962-8924(94)90066-3)

Kaczmarczyk SJ, Andrikopoulos S, Favaloro J, Domenighetti AA, Dunn A, Ernst M, Grail D, Fodero-Tavoletti M, Huggins CE, Delbridge LM et al. 
2003 Threshold effects of glucose transporter-4 (GLUT4) deficiency on cardiac glucose uptake and development of hypertrophy. Journal of Molecular Endocrinology 31 449-459. (doi:10.1677/jme.0.0310449)

Kahn BB 1992 Facilitative glucose transporters: regulatory mechanisms and dysregulation in diabetes. Journal of Clinical Investigation 89 1367-1374. (doi:10.1172/JCI115724)

Kahn BB 1994 Dietary regulation of glucose transporter gene expression: tissue specific effects in adipose cells and muscle. Journal of Nutrition $\mathbf{1 2 4}$ 1289S-1295S.

Kahn SE, Hull RL \& Utzschneider KM 2006 Mechanisms linking obesity to insulin resistance and type 2 diabetes. Nature 444 840-846. (doi:10.1038/ nature05482)

Katz EB, Stenbit AE, Hatton K, DePinho R \& Charron MJ 1995 Cardiac and adipose tissue abnormalities but not diabetes in mice deficient in GLUT4. Nature 377 151-155. (doi:10.1038/377151a0)

Kebede M, Favaloro J, Gunton JE, Laybutt DR, Shaw M, Wong N, Fam BC, Aston-Mourney K, Rantzau C, Zulli A et al. 2008 Fructose-1,6bisphosphatase overexpression in pancreatic $\beta$-cells results in reduced insulin secretion: a new mechanism for fat-induced impairment of $\beta$-cell function. Diabetes 57 1887-1895. (doi:10.2337/db07-1326)

Kim JK, Zisman A, Fillmore JJ, Peroni OD, Kotani K, Perret P, Zong H, Dong J, Kahn CR, Kahn BB et al. 2001 Glucose toxicity and the development of diabetes in mice with muscle-specific inactivation of GLUT4. Journal of Clinical Investigation 108 153-160. (doi:10.1172/ JCI10294)

Koivisto UM, Martinez-Valdez H, Bilan PJ, Burdett E, Ramlal T \& Klip A 1991 Differential regulation of the GLUT-1 and GLUT-4 glucose transport systems by glucose and insulin in L6 muscle cells in culture. Journal of Biological Chemistry 266 2615-2621.

Kraegen EW, Sowden JA, Halstead MB, Clark PW, Rodnick KJ, Chisholm DJ \& James DE 1993 Glucose transporters and in vivo glucose uptake in skeletal and cardiac muscle: fasting, insulin stimulation and immunoisolation studies of GLUT1 and GLUT4. Biochemical Journal 295 287-293.

Lamont BJ, Andrikopoulos S, Funkat A, Favaloro J, Ye JM, Kraegen EW, Howlett KF, Zajac JD \& Proietto J 2003 Peripheral insulin resistance develops in transgenic rats overexpressing phosphoenolpyruvate carboxykinase in the kidney. Diabetologia 46 1338-1347. (doi:10.1007/s00125003-1180-y)

Lamont BJ, Visinoni S, Fam BC, Kebede M, Weinrich B, Papapostolou S, Massinet H, Proietto J, Favaloro J \& Andrikopoulos S 2006 Expression of human fructose-1,6-bisphosphatase in the liver of transgenic mice results in increased glycerol gluconeogenesis. Endocrinology 147 2764-2772. (doi:10.1210/en.2005-1498)

Lankarani M, Valizadeh N, Heshmat R, Peimani M \& Sohrabvand F 2009 Evaluation of insulin resistance and metabolic syndrome in patients with polycystic ovary syndrome. Gynecological Endocrinology 25 504-507. (doi:10.1080/09513590902972083)

Laybutt DR, Thompson AL, Cooney GJ \& Kraegen EW 1997 Selective chronic regulation of GLUT1 and GLUT4 content by insulin, glucose, and lipid in rat cardiac muscle in vivo. American Journal of Physiology 273 H1309-H1316.

Macheda ML, Williams ED, Best JD, Wlodek ME \& Rogers S 2003 Expression and localisation of GLUT1 and GLUT12 glucose transporters in the pregnant and lactating rat mammary gland. Cell and Tissue Research 311 91-97. (doi:10.1007/s00441-002-0661-5)

Mangiafico SP, Lim SH, Neoh S, Massinet H, Joannides CN, Proietto J, Andrikopoulos S \& Fam BC 2011 A primary defect in glucose production alone cannot induce glucose intolerance without defects in insulin secretion. Journal of Endocrinology 210 335-347. (doi:10.1530/JOE11-0126)

Marette A, Richardson JM, Ramlal T, Balon TW, Vranic M, Pessin JE \& Klip A 1992 Abundance, localization, and insulin-induced translocation of glucose transporters in red and white muscle. American Journal of Physiology 263 C443-C452.

Marshall BA, Ren JM, Johnson DW, Gibbs EM, Lillquist JS, Soeller WC, Holloszy JO \& Mueckler M 1993 Germline manipulation of glucose homeostasis via alteration of glucose transporter levels in skeletal muscle. Journal of Biological Chemistry 268 18442-18445.
Mueckler M 1994 Facilitative glucose transporters. European Journal of Biochemistry 219 713-725. (doi:10.1111/j.1432-1033.1994.tb18550.x)

Pendergrass M, Bertoldo A, Bonadonna R, Nucci G, Mandarino L, Cobelli C \& Defronzo RA 2007 Muscle glucose transport and phosphorylation in type 2 diabetic, obese nondiabetic, and genetically predisposed individuals. American Journal of Physiology. Endocrinology and Metabolism 292 E92-E100. (doi:10.1152/ajpendo.00617.2005)

Perseghin G, Ghosh S, Gerow K \& Shulman GI 1997 Metabolic defects in lean nondiabetic offspring of NIDDM parents: a cross-sectional study. Diabetes 46 1001-1009. (doi:10.2337/diabetes.46.6.1001)

Purcell SH, Aerni-Flessner LB, Willcockson AR, Diggs-Andrews KA, Fisher SJ \& Moley KH 2011 Improved insulin sensitivity by GLUT12 overexpression in mice. Diabetes 60 1478-1482. (doi:10.2337/db11-0033)

Robinson R, Robinson LJ, James DE \& Lawrence JC Jr 1993 Glucose transport in L6 myoblasts overexpressing GLUT1 and GLUT4. Journal of Biological Chemistry 268 22119-22126.

Rogers S, Macheda ML, Docherty SE, Carty MD, Henderson MA, Soeller WC, Gibbs EM, James DE \& Best JD 2002 Identification of a novel glucose transporter-like protein-GLUT-12. American Journal of Physiology. Endocrinology and Metabolism 282 E733-E738.

Rossetti L, Stenbit AE, Chen W, Hu M, Barzilai N, Katz EB \& Charron MJ 1997 Peripheral but not hepatic insulin resistance in mice with one disrupted allele of the glucose transporter type 4 (GLUT4) gene. Journal of Clinical Investigation 100 1831-1839. (doi:10.1172/JCI119711)

Ryder JW, Kawano Y, Chibalin AV, Rincon J, Tsao TS, Stenbit AE, Combatsiaris T, Yang J, Holman GD, Charron MJ et al. 1999a In vitro analysis of the glucose-transport system in GLUT4-null skeletal muscle. Biochemical Journal 342 321-328. (doi:10.1042/ 0264-6021:3420321)

Ryder JW, Kawano Y, Galuska D, Fahlman R, Wallberg-Henriksson H, Charron MJ \& Zierath JR $1999 b$ Postexercise glucose uptake and glycogen synthesis in skeletal muscle from GLUT4-deficient mice. FASEB Journal 13 2246-2256.

Shepherd PR \& Kahn BB 1999 Glucose transporters and insulin action implications for insulin resistance and diabetes mellitus. New England Journal of Medicine 341 248-257. (doi:10.1056/NEJM199907223410406)

Steinberg GR, Michell BJ, van Denderen BJ, Watt MJ, Carey AL, Fam BC, Andrikopoulos S, Proietto J, Gorgun CZ, Carling D et al. 2006 Tumor necrosis factor $\boldsymbol{\alpha}$-induced skeletal muscle insulin resistance involves suppression of AMP-kinase signaling. Cell Metabolism 4 465-474. (doi:10.1016/j.cmet.2006.11.005)

Stenbit AE, Burcelin R, Katz EB, Tsao TS, Gautier N, Charron MJ \& Le Marchand-Brustel Y 1996 Diverse effects of Glut 4 ablation on glucose uptake and glycogen synthesis in red and white skeletal muscle. Journal of Clinical Investigation 98 629-634. (doi:10.1172/JCI118833)

Stenbit AE, Tsao TS, Li J, Burcelin R, Geenen DL, Factor SM, Houseknecht K, Katz EB \& Charron MJ 1997 GLUT4 heterozygous knockout mice develop muscle insulin resistance and diabetes. Nature Medicine 3 1096-1101. (doi:10.1038/nm1097-1096)

Stenbit AE, Katz EB, Chatham JC, Geenen DL, Factor SM, Weiss RG, Tsao TS, Malhotra A, Chacko VP, Ocampo C et al. 2000 Preservation of glucose metabolism in hypertrophic GLUT4-null hearts. American Journal of Physiology. Heart and Circulatory Physiology 279 H313-H318.

Stuart CA, Howell ME, Zhang Y \& Yin D 2009 Insulin-stimulated translocation of glucose transporter (GLUT) 12 parallels that of GLUT4 in normal muscle. Journal of Clinical Endocrinology and Metabolism 94 3535-3542. (doi:10.1210/jc.2009-0162)

Stumvoll M, Goldstein BJ \& van Haeften TW 2005 Type 2 diabetes: principles of pathogenesis and therapy. Lancet 365 1333-1346. (doi:10.1016/S0140-6736(05)61032-X)

Tripathy D, Lindholm E, Isomaa B, Saloranta C, Tuomi T \& Groop L 2003 Familiality of metabolic abnormalities is dependent on age at onset and phenotype of the type 2 diabetic proband. American Journal of Physiology. Endocrinology and Metabolism 285 E1297-E1303. (doi:10.1152/ajpendo. 00113.2003) 
Utriainen T, Takala T, Luotolahti M, Ronnemaa T, Laine H, Ruotsalainen U, Haaparanta M, Nuutila P \& Yki-Jarvinen H 1998 Insulin resistance characterizes glucose uptake in skeletal muscle but not in the heart in NIDDM. Diabetologia 41 555-559. (doi:10.1007/s001250050946)

Visinoni S, Fam BC, Blair A, Rantzau C, Lamont BJ, Bouwman R, Watt MJ, Proietto J, Favaloro JM \& Andrikopoulos S 2008 Increased glucose production in mice overexpressing human fructose-1,6-bisphosphatase in the liver. American Journal of Physiology. Endocrinology and Metabolism 295 E1132-E1141. (doi:10.1152/ajpendo.90552.2008)

Visinoni S, Khalid NF, Joannides CN, Shulkes A, Yim M, Whitehead J, Tiganis T, Lamont BJ, Favaloro JM, Proietto J et al. 2012 The role of liver fructose-1,6-bisphosphatase in regulating appetite and adiposity. Diabetes 61 1122-1132. (doi:10.2337/db11-1511)

Warram JH, Martin BC, Krolewski AS, Soeldner JS \& Kahn CR 1990 Slow glucose removal rate and hyperinsulinemia precede the development of type II diabetes in the offspring of diabetic parents. Annals of Internal Medicine 113 909-915.

Wilson CM, Mitsumoto Y, Maher F \& Klip A 1995 Regulation of cell surface GLUT1, GLUT3, and GLUT4 by insulin and IGF-I in L6 myotubes. FEBS Letters 368 19-22. (doi:10.1016/0014-5793(95)00589-2)
Wong N, Blair AR, Morahan G \& Andrikopoulos S 2010 The deletion variant of nicotinamide nucleotide transhydrogenase (Nnt) does not affect insulin secretion or glucose tolerance. Endocrinology 151 96-102. (doi:10.1210/en.2009-0887)

Wong N, Fam BC, Cempako GR, Steinberg GR, Walder K, Kay TW, Proietto J \& Andrikopoulos S 2011 Deficiency in interferon- $\gamma$ results in reduced body weight and better glucose tolerance in mice. Endocrinology 152 3690-3699. (doi:10.1210/en.2011-0288)

Zisman A, Peroni OD, Abel ED, Michael MD, Mauvais-Jarvis F, Lowell BB, Wojtaszewski JF, Hirshman MF, Virkamaki A, Goodyear LJ et al. 2000 Targeted disruption of the glucose transporter 4 selectively in muscle causes insulin resistance and glucose intolerance. Nature Medicine 6 924-928. (doi:10.1038/78693)

Received in final form 19 June 2012

Accepted 25 June 2012

Made available online as an Accepted Preprint 25 June 2012 